\title{
Comorbid depression and anxiety effects on pregnancy and neonatal outcome
}

\author{
Tiffany Field ${ }^{\mathrm{a}, \mathrm{b}, *}$, Miguel Diego $^{\mathrm{a}}$, Maria Hernandez-Reif ${ }^{\mathrm{c}}$, Barbara Figueiredo $^{\mathrm{d}}$, \\ Osvelia Deeds ${ }^{\mathrm{a}}$, Angela Ascencio ${ }^{\mathrm{a}}$, Saul Schanberg ${ }^{\mathrm{e}}$, Cynthia Kuhn ${ }^{\mathrm{e}}$ \\ a Touch Research Institute, University of Miami Medical School, United States \\ b Fielding Graduate University, United States \\ c University of Alabama, United States \\ d University of Minho, Portugal \\ e Duke University Medical School, United States
}

\section{A R T I C L E I N F O}

\section{Article history:}

Received 19 May 2009

Received in revised form 21 October 2009

Accepted 23 October 2009

\section{Keywords:}

Comorbid depression

Anxiety

Pregnancy

Neonatal outcome

\begin{abstract}
A B S T R A C T
The effects of comorbid depression and anxiety were compared to the effects of depression alone and anxiety alone on pregnancy mood states and biochemistry and on neonatal outcomes in a large multi-ethnic sample. At the prenatal period the comorbid and depressed groups had higher scores than the other groups on the depression measure. But, the comorbid group had higher anxiety, anger and daily hassles scores than the other groups, and they had lower dopamine levels. As compared to the non-depressed group, they also reported more sleep disturbances and relationship problems. The comorbid group also experienced a greater incidence of prematurity than the depressed, the high anxiety and the nondepressed groups. Although the comorbid and anxiety groups were lower birthweight than the non-depressed and depressed groups, the comorbid group did not differ from the depressed and anxiety groups on birth length. The neonates of the comorbid and depressed groups had higher cortisol and norepinephrine and lower dopamine and serotonin levels than the neonates of the anxiety and non-depressed groups as well as greater relative right frontal EEG. These data suggest that for some measures comorbidity of depression and anxiety is the worst condition (e.g., incidence of prematurity), while for others, comorbidity is no more impactful than depression alone.
\end{abstract}

(c) 2009 Elsevier Inc. All rights reserved.

\section{Introduction}

Prenatal depression has been noted to have negative effects on fetal growth and neonatal outcome including a greater incidence of prematurity and low birthweight (Field et al., 2004; Jesse, Seaver, \& Wallace, 2003; Moncuso, Schetter, Rini, Roesch, \& Hobel, 2004). Pregnancy anxiety has also been noted for negative neonatal outcomes including a greater incidence of low birthweight and prematurity (Rondo et al., 2003). Although some studies have targeted depressed women during pregnancy and have reported elevated anxiety and anger scores in those women (Field et al., 2003, 2005), less is known about the comorbid condition of depression and anxiety during pregnancy and its influence on fetal and neonatal development.

\footnotetext{
* Corresponding author at: Touch Research Institute, University of Miami School of Medicine, PO Box 016820, Miami, FL, 33101, United States. Tel.: +1 3052436781 .

E-mail address: tfield@med.miami.edu (T. Field).
} 
Current estimates of the incidence of prenatal depression range from $20 \%$ to as high as $40 \%$ (Andersson, SundstromPoromaa, Wulff, Astrom, \& Bixo, 2006), higher rates than the recent figures on postpartum depression (17\%). The greater incidence may explain the increasing focus on prenatal depression effects on the fetus and neonate. In a recent study, we documented the effects of prenatal depression on prematurity and low birthweight (Field et al., 2004). The prenatally depressed women versus non-depressed women had higher urinary cortisol levels and lower dopamine and serotonin levels, and they were more likely to deliver prematurely and have low birthweight babies. The newborns of the depressed mothers had higher cortisol levels and lower dopamine and serotonin levels, thus mimicking their mothers' prenatal levels. The newborns of depressed mothers also had greater relative right frontal EEG activation and lower vagal tone than the neonates of non-depressed mothers. Finally, they received lower scores on the Brazelton Neonatal Behavioral Assessment Scale. A path analysis on the effects of the mothers' prenatal depression and biochemical profile on their newborns' gestational age and birthweight suggested that prenatal depression was predictive of prenatal cortisol and norepinephrine levels and prenatal cortisol levels, in turn, predicted prematurity and low birthweight. Given that prenatal cortisol contributed to only $28 \%$ of the variance, other factors such as infections and illness during pregnancy may have contributed to this prematurity rate. For example, prolonged sick leave, increased nausea and vomiting and increased number of visits to the obstetrician have been reported in depressed pregnant women in at least one sample (Andersson, Sundstrom-Poromaa, Wulff, Astrom, \& Bixo, 2004).

Prenatal anxiety effects on the fetus and neonate have included increased uterine artery resistance leading to reduced blood flow to the fetus (Glover, Teixeira, Gitau, \& Fisk, 1999). This same group of investigators also implicated cortisol and norepinephrine as potential mediators of the effects of anxiety on intrauterine artery resistance and ultimately low birthweight (Teixeira, Fisk, \& Glover, 1999). Prenatal anxiety is also thought to lead to a greater incidence of low birthweight and prematurity (Rondo et al., 2003). Elevated anxiety and anxiety disorders during pregnancy have also been associated with lower apgar scores (Berle et al., 2005). Just as prenatal depression predicts to postnatal depression, and prenatal anxiety predicts to postpartum anxiety (Herson et al., 2004), prenatal anxiety in this study was also noted to predict postnatal depression at 8 weeks and at 8 months. It is perhaps not surprising, then, that prenatal and postnatal anxiety may contribute to colic (Canivet, Ostergren, Rosen, Jakobsson, \& Hagander, 2005) as well as more difficult temperament during later infancy (Austin, Hadzi-Pavlovic, Leader, Saint, \& Parker, 2005). And, longer term effects have been noted, for example, atypical handedness at 42 months (Glover, O’Connor, Heron, Golding, \& ALSPAC Study Team, 2004) and behavior problems at 4 years (O'Connor, Heron, Glover, \& ALSPAC Study Team 2002; O'Connor, Heron, Golding, Beveridge, \& Glover, 2002).

Although anxiety and depression are thought to be two separate disorders, they occur comorbidly in as many as 30-58\% of patients with major depression disorder (Pollack, 2005; Young, Abelson, \& Cameron, 2004). Patients with depression and comorbid anxiety symptoms versus those with depression alone have been noted to have more severe depressive symptoms, longer depressive episodes, a more chronic course, worse psychosocial impairment, a poorer response to medication, less recovery from the index episode and increased suicidality (Pollack, 2005). The effects may be more than simply additive even though prenatal depression and prenatal anxiety as individual disorders might be expected to have similar effects on the fetus and neonate. Some have suggested, however, that anxiety and depression have different effects and that they may operate by different mechanisms (Glover et al., 1999). Anxiety and depression are more likely to be comorbid than noncomorbid in pregnant women, and, thus, the effects may combine by still a third mechanism. The more typical condition, i.e., comorbidity of anxiety and depression may lead to both shorter gestational age and reduced birthweight than either condition alone. The data from the separate literatures on prenatal depression and prenatal anxiety effects may have been confounded by this comorbidity.

The purpose of the present study was to explore the separate effects of prenatal depression and anxiety and the effects of comorbid depression and anxiety on: (1) mothers' mood states including depression, anxiety and anger and on their daily hassles and sleep disturbances as well as their EEG and biochemistry (cortisol, norepinephrine, epinephrine, dopamine and serotonin) at the prenatal and the neonatal periods; and (2) neonatal outcomes including birth measures and the same biochemical measures and EEG that were taken for the mothers. Comorbid depression and anxiety effects were expected to be worse than depression or anxiety effects alone.

\section{Method}

\subsection{Participants}

Nine-hundred and eleven pregnant women were recruited during their second trimester of pregnancy ( $M=20$ weeks gestation). The women were assigned to 4 groups based on the Structural Clinical Interview for DSM-IV Disorders as follows: (1) Non-depressed or No Diagnosis $(N=345)$; (2) Anxiety Disorder $(N=77)$; (3) Depressive Disorder $(N=181)$; and (4) Comorbid Anxiety-Depressive Disorder $(N=308)$. They were contacted before their ultrasound examination at a large urban University Hospital. Women were excluded from participation in the study if they (1) were less than 18 years old, (2) had multiple fetuses and (3) reported HIV/AIDS status or medical complications.

The women were between 18 and 40 years old $(M=27.5)$ and their mean parity was 1.2 with $57 \%$ of the sample being primiparous. The sample was comprised of women with a college (25\%) or a high school degree or less (46\%). The women had a predominantly low to middle socioeconomic status $(M=3.7$ on the Hollingshead Two-factor Index of Social Status). 
The women's ethnicity was distributed 59\% Hispanic, 32\% Black and 9\% Caucasian. Most of the women were in a relationship (95\%). The 4 groups did not differ on these demographic variables.

\subsection{Procedures}

The women were recruited at the prenatal clinics of a university hospital by trained female interviewers. The women who expressed interest in participating in this study (approximately 80\%) were asked to sign an informed consent and to participate in approximately one hour of assessments. Then the women were interviewed to obtain demographic data, and they were given the SCID for a diagnosis, as well as the Center for Epidemiological Studies-Depression scale (CES-D) (Radloff, 1977), the State Anxiety Inventory (STAI) (Spielberger, Gorsuch, \& Lushene, 1970), the State Anger Inventory (STAXI) (Spielberger, Ritterband, Sydeman, Reheiser, \& Unger, 1995), the Behavioral Inhibition Scale (BIS) (Carver \& White, 1994) the Daily Hassles Scale (Field et al., 2003), the Sleep Disturbance Scale (Verran \& Snyder-Halpern, 1988) and the Relationship Questionnaire (Figuereido, Field, Hernandez-Reif, \& Diego, 2007). The women also provided a urine sample to be assayed for cortisol and the metabolites of norepinephrine, epinephrine, dopamine and serotonin.

\subsection{Instruments}

Structured Clinical Interview for DSM-IV Disorders (SCID): All women in the study were given the SCID (research version) to determine depression and anxiety diagnoses and to screen out other disorders including bipolar disorder, schizophrenia and other psychotic disorders. The women who were diagnosed with Dysthymia or Major Depression or Anxiety Disorder on the SCID based on DSM IV symptoms and mothers who were free of any diagnosis (the non-depressed group) were eligible for the study. The SCID was administered by female research associates following training and with continuing supervision by a clinical psychologist. Almost all of the depressed pregnant women (98\%) were not taking anti-depressants and were not receiving other treatments for depression.

The Center for Epidemiology Studies-Depression Scale (CES-D) is a 20-item scale that assesses the frequency of depressive symptoms within the last week. With scores ranging from 0 to 60 , a cut-off score of 16 is used for classifying a major depressive episode. With only a $6 \%$ false positive and $36 \%$ false negative rate (Myers \& Weissman, 1980), this scale has been shown to be reliable and valid for diverse demographic groups (Radloff, 1977) and has been successfully used as a self-report assessment of depression in a number of studies that involved similar populations (Diego et al., 2004).

The State Anxiety Inventory (STAI) is comprised of 20 items and assesses the intensity of anxiety symptoms. The scores range from 20 to 90, and the cut-off for high anxiety is 48 . Research has demonstrated that the STAI has adequate concurrent validity and internal consistency (Spielberger et al., 1970), and the scale has been used in several studies with pregnant women (e.g., Da Costa, Larouche, Dritsa, \& Brender, 2000).

State Anger Inventory (STAXI) (Spielberger, Ritterband, Sydeman, Reheiser, \& Unger, 1995) is a 10-item inventory that assesses general feelings of anger based on a 4-point Likert scale ranging from 1 (almost never) to 4 (almost always). Typical questions include "I am quick tempered" and "I fly off the handle". Psychometric properties have been established for the STAXI on diverse ethnic groups including a test-retest reliability coefficient of 0.97 .

The Behavioral Inhibition Scale (BIS) (Carver \& White, 1994): The BIS is a 24-item questionnaire consisting of personal statements followed by 4 severity options ranging from very true to very false. Scores can range from 24 to 96 . The BIS is designed to assess the tendency to behave in response to reward or in response to punishment. High Behavioral Inhibition System (BIS) scores reflect withdrawal behavior.

Daily Hassles Scale (Field et al., 2003): This scale was developed to assess the degree of hassle being experienced by expectant mothers. The 16 items on a 4-point Likert scale include questions on people such as family members, landlord and friends and finances creating hassles.

Sleep Disturbance Scale (Verran \& Snyder-Halpern, 1988): Questions on this 15-item scale are rated on a visual analogue anchored at one end with effective sleep responses (e.g., "Did not awaken," "Had no trouble sleeping") and at the opposite end with ineffective responses (e.g., "Was awake $10 \mathrm{~h}$," "Had a lot of trouble falling asleep"). The participants place a mark across the answer line at the point that best reflects their last night's sleep. A reliability coefficient of 82 has been reported for this scale. The sleep disturbance subscale was used in this study.

The Relationship Questionnaire (Figuereido et al., 2007) is comprised of 12 items on a 4-point Likert scale and is focused on positive and negative aspects of spouse/partner relationships. The positive dimensions include a sense of support and care, as well as satisfaction, closeness and joint interests and activities, and the negative dimensions include, for example, anxiety, irritability and criticisms that have been associated with undesirable outcomes. Data for this measure were available for $95 \%$ of the sample (95\% of the women being in relationships with a spouse or partner).

Pregnancy Stress Questions (Field, 2007): This questionnaire includes 3 questions that address pregnancy stress including; "Have you had any stressful situations during pregnancy", "Are you unhappy about being pregnant?", and "Is your partner unhappy about being pregnant?".

Urinary catecholamines and metabolites: Urinary samples were collected mid-morning from the women at the beginning of the 20 and 32 week gestation visits and from the neonates within the first two days post-delivery. No systematic differences were noted in the sampling or the timing of collection of urine samples between women. Urine samples were transferred to plastic vials and frozen without using acid or other preservatives and shipped to Duke University Medical School. The assays 
Table 1

Means for prenatal self-report variables for non-depressed, anxiety, depressed and comorbid depression and anxiety groups (S.D. in parentheses). Different letter superscripts denote differences between group means.

\begin{tabular}{|c|c|c|c|c|c|c|}
\hline \multicolumn{7}{|l|}{ Group } \\
\hline & Non-depressed & Anxiety & Depressed & Comorbid & $F$ & $p$ \\
\hline \multicolumn{7}{|l|}{ Measures } \\
\hline \multicolumn{7}{|l|}{ Prenatal early GA (20 weeks) } \\
\hline Depression (CES-D) & $8.45^{\mathrm{a}}(3.84)$ & $10.51^{\mathrm{b}}(3.71)$ & $22.11^{c}(5.96)$ & $27.15^{\mathrm{c}}(7.60)$ & 661.37 & .000 \\
\hline Anxiety (STAI) & $30.74^{\mathrm{a}}(5.06)$ & $45.57^{\mathrm{b}}(5.16)$ & $33.85^{c}(5.27)$ & $50.18^{\mathrm{d}}(7.07)$ & 694.14 & .000 \\
\hline Anger (STAXI) & $15.96^{\mathrm{a}}(4.14)$ & $18.12^{\mathrm{b}}(4.51)$ & $19.58^{\mathrm{b}}(6.20)$ & $22.18^{\mathrm{c}}(6.05)$ & 62.72 & .000 \\
\hline Behavioral inhibition (BIS) & $17.66^{\mathrm{a}}(3.55)$ & $18.15^{\mathrm{ab}}(3.31)$ & $18.46^{\mathrm{ab}}(4.30)$ & $18.63^{\mathrm{b}}(3.78)$ & 3.37 & .02 \\
\hline Daily Hassles & $19.31^{\mathrm{a}}(5.48)$ & $22.91^{\mathrm{b}}(5.41)$ & $22.77^{\mathrm{b}}(7.87)$ & $27.50^{c}(7.63)$ & 46.28 & .000 \\
\hline Sleep disturbances & $37.60^{\mathrm{a}}(22.61)$ & $44.80^{\mathrm{ab}}(13.38)$ & $44.09^{\mathrm{ab}}(24.66)$ & $48.02^{\mathrm{b}}(20.82)$ & 2.90 & .04 \\
\hline Relationships & $2.21^{\mathrm{a}}(0.88)$ & $1.33^{\mathrm{ab}}(0.94)$ & $1.04^{\mathrm{ab}}(1.07)$ & $0.78^{\mathrm{b}}(1.18)$ & 2.93 & .05 \\
\hline \multicolumn{7}{|l|}{ Prenatal late GA (32 weeks) } \\
\hline Depression (CES-D) & $11.70^{\mathrm{a}}(7.20)$ & $12.18^{\mathrm{a}}(6.92)$ & $17.29^{b}(10.26)$ & $19.37^{\mathrm{b}}(9.08)$ & 7.78 & .000 \\
\hline Anxiety (STAI) & $37.91^{\mathrm{a}}(9.05)$ & $37.06^{\mathrm{a}}(10.27)$ & $41.69^{\mathrm{ab}}(9.72)$ & $44.75^{\mathrm{b}}(9.66)$ & 5.53 & .001 \\
\hline Anger (STAXI) & $16.35(4.44)$ & $17.22(5.36)$ & $19.44(8.01)$ & $19.64(7.46)$ & 2.06 & .11 \\
\hline Daily Hassles & $19.50^{\mathrm{a}}(5.71)$ & $24.00^{\mathrm{b}}(5.23)$ & $24.00^{\mathrm{b}}(5.41)$ & $28.50^{\mathrm{c}}(4.24)$ & 14.62 & .03 \\
\hline Sleep disturbances & $40.48^{a}(21.89)$ & $48.60^{\mathrm{ab}}(21.47)$ & $46.63^{\mathrm{ab}}(20.61)$ & $54.93^{\mathrm{b}}(19.18)$ & 4.14 & .008 \\
\hline \multicolumn{7}{|l|}{ Postnatal (2 days) } \\
\hline Depression (CES-D) & $10.49^{\mathrm{a}}(7.35)$ & $12.94^{\mathrm{ab}}(7.65)$ & $15.95^{\mathrm{b}}(9.01)$ & $21.22^{c}(10.26)$ & 46.52 & .000 \\
\hline Anxiety (STAI) & $32.22^{\mathrm{a}}(6.59)$ & $40.70^{\mathrm{b}}(8.01)$ & $34.40^{\mathrm{a}}(7.61)$ & $43.89^{\mathrm{bc}}(10.58)$ & 58.90 & .000 \\
\hline Anger (STAXI) & $15.80^{\mathrm{a}}(4.45)$ & $18.45^{\mathrm{b}}(4.71)$ & $17.49^{\mathrm{b}}(5.97)$ & $19.40^{c}(5.26)$ & 13.92 & .000 \\
\hline Sleep disturbances & $47.12(20.37)$ & $43.45(20.75)$ & $41.01(12.53)$ & $58.91(14.62)$ & 2.13 & .11 \\
\hline
\end{tabular}

were conducted by high-pressure liquid chromatography with electrochemical detection (Kilts, Gooch, \& Knopes, 1984). Urinary levels of the norepinephrine, dopamine, and serotonin metabolites were measured, as the majority of excreted catecholamines and serotonin respectively exist in the form of metabolites. Urinary cortisol was assayed in the stored urine samples by radioimmunoassay using a specific antiserum from Radioassay Systems Laboratories (Carson City, CA). Bound and free hormones are separated by the dextran-coated charcoal technique. The sensitivity of the assay is 0.025 ng/tube. The inter-assay and intra-assay coefficient of variation is less than $10 \%$ and $5 \%$ respectively. All values were corrected for creatinine volume. The elution of cortisol and the internal standard were then done on a reverse phase chromatographic system (Bondapak C column and methanol:water mobile phase).

These assays were conducted because in at least two other samples we have noted increased cortisol and decreased metabolites of dopamine and serotonin in depressed pregnant women and their newborns (Field et al., 2004; Lundy et al., 1999). Similarly, Glover et al. (1999) have reported elevated levels of cortisol and norepinephrine in pregnant women with high anxiety levels. Thus, we would expect the comorbid group to have higher levels than the depressed and anxiety groups.

\section{Results}

As can be seen in Table 1, on the self-report measures: (1) for the prenatal early gestation (20 weeks) period, separate ANOVAs with group as the independent measure and each of the self-report scales as the dependent measures revealed that the comorbid group had (a) similar depression (CES-D) scores as the depressed group but worse depression scores than the other groups; (b) worse scores than all groups for anxiety (STAI), anger (STAXI) and Daily Hassles; and (c) worse than the non-depressed group but the same as the depressed and anxiety groups on sleep disturbances, relationships and behavioral inhibition scales; and (2) for the prenatal late gestation (32 weeks) period, separate ANOVAs suggested that the comorbid group had: (a) worse scores than the other groups for depression and anger; and (b) similar scores as the anxiety group on anxiety but, in turn, worse anxiety scores than the other groups.

As can be seen in Table 2, ANOVAs on the biochemistry variables revealed the following: (1) the lowest dopamine levels at both the early and late gestational age periods for the comorbid group mothers; (2) the highest epinephrine levels for the comorbid group mothers at the postnatal period; and (3) higher cortisol and norepinephrine levels in the newborns of the comorbid and depressed mothers and lower dopamine and serotonin levels in those groups of newborns.

The separate ANOVAs on neonatal outcome variables (Table 3) suggest that the newborns of the comorbid group: (1) had a greater incidence of prematurity than the other groups; (2) had lower birthweight and birth length than the neonates of the non-depressed mothers, but the neonates of the comorbid mothers were equivalent to the neonates of the depressed mothers on birth length and to the neonates of the anxiety group on both birthweight and birth length; (3) the comorbid depressed/anxiety mothers had greater relative right frontal EEG activation than the non-depressed mothers, but they were equivalent to the mothers in the depressed and anxiety groups; and (4) the neonates of the comorbid group mothers had greater relative right frontal EEG activation than the neonates of the non-depressed and anxiety mothers, although they were equivalent to the neonates of the depressed mothers. 
Table 2

Means for biochemical variables (in $\mathrm{ng} / \mathrm{ml}$ ) for non-depressed, anxiety, depressed and comorbid depression and anxiety groups (S.D. in parentheses). Different letter superscripts denote differences between group means.

\begin{tabular}{|c|c|c|c|c|c|c|}
\hline \multicolumn{7}{|l|}{ Group } \\
\hline & Non-depressed & Anxiety & Depressed & Comorbid & $F$ & $p$ \\
\hline \multicolumn{7}{|l|}{ Measures } \\
\hline \multicolumn{7}{|c|}{ Prenatal early GA (20 weeks) } \\
\hline Cortisol & $200.74(114.12)$ & $173.64(119.88)$ & $197.11(123.60)$ & $200.76(112.20)$ & & NS \\
\hline Norepinephrine & $52.00(23.10)$ & $63.95(27.44)$ & $55.75(25.48)$ & $59.93(25.24)$ & 1.93 & .12 \\
\hline Epinephrine & $4.74(3.18)$ & $5.90(2.83)$ & $5.31(4.73)$ & $5.93(4.00)$ & & \\
\hline Dopamine & $287.49^{\mathrm{a}}(114.93)$ & $361.91^{\mathrm{b}}(176.73)$ & $272.89^{\mathrm{ac}}(114.11)$ & $265.41^{\mathrm{c}}(124.83)$ & 3.38 & .02 \\
\hline Serotonin & $3993.20(2071.66)$ & $4595.07(2316.06)$ & $3882.18(2045.36)$ & $4026.63(2470.32)$ & & NS \\
\hline \multicolumn{7}{|c|}{ Prenatal late GA (32 weeks) } \\
\hline Cortisol & $190.04(100.64)$ & $200.71(181.71)$ & $168.82(86.89)$ & $219.81(142.09)$ & & NS \\
\hline Norepinephrine & $45.32^{\mathrm{a}}(30.24)$ & $63.06^{\mathrm{b}}(18.00)$ & $45.41^{\mathrm{a}}(19.86)$ & $54.58^{\mathrm{b}}(28.88)$ & & NS \\
\hline Epinephrine & $3.35^{\mathrm{a}}(3.41)$ & $4.08^{\mathrm{b}}(3.20)$ & $2.62^{\mathrm{c}}(1.05)$ & $4.03^{\mathrm{b}}(3.49)$ & & NS \\
\hline Dopamine & $189.69^{\mathrm{a}}(109.52)$ & $275.64^{\mathrm{b}}(99.37)$ & $196.42^{\mathrm{a}}(116.43)$ & $159.07^{\mathrm{c}}(144.07)$ & 3.03 & .05 \\
\hline Serotonin & $2638.01(1783.53)$ & $4358.87(2702.63)$ & $2144.77(1258.73)$ & $2964.10(1992.86)$ & & NS \\
\hline \multicolumn{7}{|c|}{ Postnatal-mother (2 days) } \\
\hline Cortisol & $162.30^{\mathrm{a}}(96.21)$ & $120.28^{\mathrm{b}}(73.19)$ & $228.40^{\mathrm{c}}(176.07)$ & $209.73^{c}(184.65)$ & 2.18 & .10 \\
\hline Norepinephrine & $31.28^{\mathrm{a}}(13.700$ & $31.45^{\mathrm{a}}(21.01)$ & $39.15^{\mathrm{b}}(34.47)$ & $43.37^{b}(29.49)$ & & NS \\
\hline Epinephrine & $4.67^{\mathrm{a}}(2.93)$ & $2.60^{\mathrm{b}}(1.17)$ & $4.59^{\mathrm{a}}(1.63)$ & $6.17^{c}(2.11)$ & 2.71 & .05 \\
\hline Dopamine & $246.85(89.84)$ & $270.37(106.87)$ & $232.19(155.89)$ & $192.95(105.08)$ & & NS \\
\hline Serotonin & $4552.90(3617.89)$ & $2962.96(1881.94)$ & $2985.05(815.44)$ & $4679.32(2315.05)$ & & NS \\
\hline \multicolumn{7}{|l|}{ Neonate } \\
\hline Cortisol & $360.58^{a}(230.53)$ & $272.87^{\mathrm{b}}(270.44)$ & $469.81^{\mathrm{c}}(296.31)$ & $455.38^{c}(262.70)$ & 3.08 & .05 \\
\hline Norepinephrine & $54.80^{\mathrm{a}}(36.10)$ & $60.00^{\mathrm{ab}}(102.32)$ & $63.75^{\mathrm{b}}(26.15)$ & $62.13^{\mathrm{b}}(24.08)$ & 4.25 & .009 \\
\hline Epinephrine & $29.07(86.91)$ & $7.02(7.29)$ & $5.62(2.93)$ & $5.07(2.95)$ & & NS \\
\hline Dopamine & $530.16^{\mathrm{a}}(258.48)$ & $525.68^{a}(486.38)$ & $366.76^{\mathrm{b}}(129.36)$ & $395.96^{\mathrm{b}}(227.39)$ & 3.80 & .05 \\
\hline Serotonin & $3909.02^{\mathrm{a}}(2088.58)$ & $3459.95^{\mathrm{a}}(2463.21)$ & $2204.01^{\mathrm{b}}(2106.08)$ & $2553.72^{\mathrm{b}}(2142.39)$ & 3.27 & .05 \\
\hline
\end{tabular}

Table 3

Means for neonatal outcome variables.

\begin{tabular}{|c|c|c|c|c|c|c|}
\hline \multicolumn{7}{|l|}{ Group } \\
\hline & Non-depressed & Anxiety & Depressed & Comorbid & $F$ & $p$ \\
\hline \multicolumn{7}{|l|}{ Measures } \\
\hline Prematurity (\%) & $6.0^{\mathrm{a}}$ & $10.2^{\mathrm{b}}$ & $6.5^{\mathrm{a}}$ & $14.5^{\mathrm{c}}$ & 11.26 & .01 \\
\hline Birthweight & $3352.17^{\mathrm{a}}(448.26)$ & $3195.76^{\mathrm{b}}(347.75)$ & $3355.57^{a}(404.14)$ & $3224.29^{b}(483.42)$ & 4.80 & .003 \\
\hline Birth length & $50.66^{\mathrm{a}}(3.16)$ & $50.40^{\mathrm{ab}}(1.40)$ & $50.75^{\mathrm{ab}}(3.56)$ & $49.56^{\mathrm{b}}(4.96)$ & 2.64 & .05 \\
\hline \multicolumn{7}{|l|}{ EEG } \\
\hline Mother & $.02^{\mathrm{a}}(.13)$ & $-.07^{\mathrm{ab}}(.20)$ & $-.12^{\mathrm{ab}}(.24)$ & $-.16^{\mathrm{b}}(.19)$ & 4.14 & .01 \\
\hline Infant & $.03^{\mathrm{a}}(.10)$ & $.10^{\mathrm{a}}(.26)$ & $-.05^{\mathrm{b}}(.15)$ & $-.08^{\mathrm{b}}(.15)$ & 5.07 & .003 \\
\hline
\end{tabular}

Table 4

Means for potential confounding variables.

\begin{tabular}{|c|c|c|c|c|c|c|}
\hline \multicolumn{7}{|l|}{ Group } \\
\hline & Non-depressed & Anxiety & Depressed & Comorbid & $X^{2}$ & $p$ \\
\hline \multicolumn{7}{|l|}{ Measures } \\
\hline Stressful situation during pregnancy (\%) & $32.9^{\mathrm{a}}$ & $43.3^{b}$ & $43.5^{b}$ & $59.6^{c}$ & 40.07 & .000 \\
\hline Unhappy about pregnancy (\%) & $13.2^{\mathrm{a}}$ & $13.4^{\mathrm{a}}$ & $25.5^{\mathrm{b}}$ & $32.8^{\mathrm{c}}$ & 34.53 & .000 \\
\hline Partner unhappy about pregnancy (\%) & $9.1^{\mathrm{a}}$ & $10.4^{\mathrm{a}}$ & $18.2^{\mathrm{b}}$ & $19.5^{b}$ & 14.76 & .002 \\
\hline
\end{tabular}

Table 4 results suggest group differences on potential confounding variables including the comorbid group having: (1) a greater incidence of "a stressful situation during pregnancy" than the other groups; (2) a greater incidence of "being unhappy about the pregnancy"; and (3) a greater incidence of the partner "being unhappy about the pregnancy", although the incidence of the partners being unhappy in the comorbid group was similar to the incidence for the depressed group.

\section{Discussion}

These data on pregnant women with comorbid depression/anxiety disorder are consistent with data in the literature on comorbidity in non-pregnant adults (Pollack, 2005; Young et al., 2004), although the pregnant women in this study did not report more severe depressive symptoms than the depression-only women. They did, however, report more anxiety 
and anger symptoms than the anxiety and depression disorder groups at the early gestation period, although they did not differ from the depression group at the late gestation period. Although the comorbid group was no worse than the other disorder groups on the Behavioral Inhibition, Sleep Disturbances and Relationship Scales, they did report more potentially confounding problems including more frequent daily hassles, "stressful situations during pregnancy" and more often "being unhappy about the pregnancy".

Although we did not compare the groups across the early and late gestation periods, the early gestation differences between the comorbid and depression groups tended to disappear by late gestation except that the comorbid group had the lowest dopamine levels during the late gestational age period. It is not clear what this means except that dopamine is an activating transmitter that is notably low in very depressed individuals and may have contributed to the comorbid group having a greater incidence of prematurity.

The greater incidence of prematurity noted for the neonates of the comorbid group highlights the additive effects of prenatal depression and anxiety on neonatal outcomes. However, the comorbid group newborns were equivalent to the anxiety group newborns on their lower birthweight, and they were equivalent to both the anxiety and the depressed group newborns on their lower birth length. In addition, although the right frontal EEG patterns of the comorbid mothers did not differ from those of the mothers in the other disorder groups, greater right frontal EEG activation was noted in the neonates of the comorbid and depressed groups versus the anxiety and non-depressed groups.

Finally, the cortisol and norepinephrine levels of the neonates in the comorbid and depressed groups were equally higher than the levels of the newborns in the anxiety and non-depressed groups, and the dopamine and serotonin levels of the newborns of the comorbid and the depressed mother groups were equally lower than the levels of these neurotransmitters in the newborns of the high anxiety and non-depressed groups. Thus, these data suggest that for some measures, comorbidity of depression and anxiety is the worst condition (e.g., a greater incidence of prematurity) while for others, comorbidity is no more impactful than depression alone or anxiety alone.

It is not clear from these data why comorbid, depression and anxiety would have additive effects given that depression and anxiety seem to be opposite mood states and would also seemingly be characterized by different biochemical profiles. The comorbid women did not appear to have higher depression scores but they did have higher anxiety, daily hassles and stress/unhappiness scores. Their dopamine levels were also lower. It is interesting, then, that the comorbid and anxiety group newborns were equivalent on low birthweight. Low birthweight has been attributed to prenatal anxiety and intrauterine artery resistance and, indirectly, to elevated norepinephrine (Teixeira et al., 1999). However, in this sample the prenatal maternal norepinephrine levels were not high in these groups, although the comorbid group neonates had higher norepinephrine levels.

These complex biochemical findings are difficult to interpret, and they illustrate the limitations of this study. The measures are indirect. The urinary metabolites are very limited measures of central nervous system metabolites, and the self-report scales are also indirect measures. The interactions of the various mood states (i.e., depression, anxiety, anger) and the various biochemical measures are perhaps too complex to measure even in large samples (albeit very unequal $\mathrm{N}$ samples) like this. Nonetheless, these data strongly suggest the need for both behavioral and biochemical studies that identify at-risk profiles, and they highlight the importance of identifying comorbidly depressed and anxious pregnant women as well as women who are only depressed or only experiencing high anxiety so that they may receive prenatal interventions to lower those levels.

\section{Acknowledgments}

We would like to thank the mothers and infants who participated in this study. This research was supported by a Merit Award (MH \#46586), an NIH grant (AT \#00370) and Senior Research Scientist Awards (MH \#0033 1 and AT \#001585) and a March of Dimes Grant (\#12-FYO3-48) to Tiffany Field and funding from Johnson and Johnson Pediatric Institute to the Touch Research Institute.

\section{References}

Andersson, L., Sundstrom-Poromaa, I., Wulff, M., Astrom, M., \& Bixo, M. (2004). Implications of antenatal depression and anxiety for obstetric outcome. Obstetrics and Gynecology, 104, 467-476.

Andersson, L., Sundstrom-Poromaa, I., Wulff, M., Astrom, M., \& Bixo, M. (2006). Depression and anxiety during pregnancy and six months postpartum: A follow-up study. Acta Obstetrics and Gynecology Scandinavica, 85, 937-944.

Austin, M., Hadzi-Pavlovic, D., Leader, L., Saint, K., \& Parker, G. (2005). Maternal trait anxiety, depression and life event stress in pregnancy: Relationships with infant temperament. Early Human Development, 81, 183-190.

Berle, J., Mykletun, A., Daltveit, A., Rasmussen, S., Holsten, F., \& Dahl, A. (2005). Neonatal outcomes in offspring of women with anxiety and depression during pregnancy. A linkage study from the Nord-Trondelag Health Study (HUNT) and Medical Birth Registry of Norway. Archives in Women Mental Health, 8, 181-189.

Canivet, C., Ostergren, P., Rosen, A., Jakobsson, I., \& Hagander, B. (2005). Infantile colic and the role of trait anxiety during pregnancy in relation to psychosocial and socioeconomic factors. Scandinavica Journal of Public Health, 33, 26-34.

Carver, C. S., \& White, T. L. (1994). Behavioral inhibition, behavioral activation, and affective responses to impending reward and punishment: The BIS/BAS scales. Scandinavica Journal of Public Health, 67, 319-333.

Da Costa, D., Larouche, J., Drista, M., \& Brender, W. (2000). Variation in stress levels over the course of pregnancy: Factors associated with elevated hassles, state anxiety and pregnancy-specific stress. Journal of Psychosomatic Research, 47, 609-621.

Diego, M., Field, T., Hernandez-Reif, M., Cullen, C., Schanberg, S., \& Kuhn, C. (2004). Prepartum, postpartum and chronic depression effects on newborns. Psychiatry, 67, 63-80. 
Field, T., 2007. Pregnancy stress questions. Unpublished scale.

Field, T., Diego, M., Dieter, J., Hernandez-Reif, M., Schanberg, S., Kuhn, C., et al. (2004). Prenatal depression effects on the fetus and the newborn. Infant Behavior and Development, 27, 216-229.

Field, T., Diego, M., Hernandez-Reif, M., Schanberg, S., Kuhn, C., Yando, R., et al. (2003). Pregnancy anxiety and comorbid depression and anger effects on the fetus and neonate. Depression and Anxiety, 17, 140-151.

Field, T., Hernandez-Reif, M., Vera, Y., Gil, K., Diego, M., Bendell, D., et al. (2005). Anxiety and anger effects on depressed mother-infant spontaneous and imitative interactions. Infant Behavior and Development, 28, 1-9.

Figuereido, B., Field, T., Hernandez-Reif, M., \& Diego, M. (2007). The relationship questionnaire. Unpublished scale.

Glover, V., O'Connor, T., Heron, J., Golding, J., \& ALSPAC Study Team. (2004). Antenatal maternal anxiety is linked with atypical handedness in the child. Early Human Development, 79, 107-118.

Glover, V., Teixeira, J., Gitau, R., \& Fisk, N. M. (1999). Mechanisms by which maternal mood in pregnancy may affect the fetus. Contemporary Review in Obstetrics and Gynaecology, 12, 1-6.

Herson, J., O'Connor, T., Evans, J., Golding, J., Glover, V., \& The ALSPAC Study Team. (2004). The course of anxiety and depression through pregnancy and the postpartum in a community sample. Journal of Affective Disorder, 80, 65-73.

Jesse, D. E., Seaver, W., \& Wallace, D. C. (2003). Maternal psychosocial risks predict preterm birth in a group of women from Appalachia. Midwifery, 19, 191-202.

Kilts, C., Gooch, M., \& Knopes, K. (1984). Journal of Neuroscience Methods, 11, 257-273.

Lundy, B. L., Jones, N. A., Field, T., Nearing, G., Davalos, M., Pietro, P., et al. (1999). Prenatal depression effects on neonates. Infant Behavior and Development, $22,121-137$

Moncuso, R. A., Schetter, C. D., Rini, C. M., Roesch, S. C., \& Hobel, C. J. (2004). Maternal prenatal anxiety and corticotropin-releasing hormone associated with timing of delivery. Psychosomatic Medicine, 66, 762-769.

Myers, J., \& Weissman, M. (1980). Use of a self-report symptom scale to detect depression in a community sample. American Journal of Psychiatry, 137, $1081-1084$.

O’Connor, T., Heron, J., Glover, V., \& ALSPAC Study Team. (2002). Antenatal anxiety predicts child behavioral/emotional problems independently of postnatal depression. Journal of American Academic of Child and Adolescent Psychiatry, 41, 1470-1477.

O’Connor, T., Heron, J., Golding, J., Beveridge, M., \& Glover, V. (2002). Maternal antenatal anxiety and children's behavioral/emotional problems at 4 years. Report from the Avon Longitudinal Study of Parents and Children. British Journal of Psychiatry, 180, 502-508.

Pollack, M. (2005). Comorbid anxiety and depression. Journal of Clinical Psychiatry, 66, 22-29.

Radloff, C. S. (1977). The CES-D Scale: A self-report depression scale for research in the general population. Applied Psychology, 3, 385-401.

Rondo, P., Ferreira, R., Nogueira, F., Ribeiro, M., Lobert, H., \& Artes, R. (2003). Maternal psychological stress and distress as predictors of low birth weight, prematurity and intrauterine growth retardation. European Journal of Clinical Nutrition, 57, 266-272.

Spielberger, C., Gorsuch, R., \& Lushene, R. (1970). The state/trait anxiety inventory. Paolo Alto, CA: Consulting Psychology Press.

Spielberger, C. D., Ritterband, L. M., Sydeman, S. J., Reheiser, E. C., \& Unger, K. K. (1995). Assessment of emotional states and personality traits: Measuring psychological vital signs. Clinical personality assessment: Practical Approaches. New York: Oxford University Press.

Teixeira, J., Fisk, N., \& Glover, V. (1999). Association between maternal anxiety in pregnancy and increased uterine artery resistance index: Cohort based study. BMJ, 318, 153-157.

Verran, J. A., \& Snyder-Halpern, R. (1988). Do patients sleep in the hospital? Applied Nursing Research, 1, 95.

Young, E., Abelson, J., \& Cameron, O. (2004). Effect of comorbid anxiety disorders on the hypothalamic-pituitary-adrenal axis response to a social stressor in major depression. Biological Psychiatry, 56, 113-120. 